\title{
Coupling cathodic Electro-Fenton with anodic photo-electrochemical oxidation: A feasibility study on the mineralization of paracetamol
}

\author{
Benjamin O. Orimolade ${ }^{\mathrm{a}}$; Busisiwe N. Zwane ${ }^{\mathrm{a}}$; Babatunde A. Koiki ${ }^{\mathrm{a}}$; Matthieu Rivallin ${ }^{\mathrm{b}}$, \\ Mikhael Bechelany ${ }^{\mathrm{b}}$, Nonhlangabezo Mabuba ${ }^{\mathrm{a}, \mathrm{c}}$; GeoffroyLesage ${ }^{\mathrm{b}}$; Marc Cretin ${ }^{\mathrm{b}}$; Omotayo A. \\ Arotiba $^{\mathrm{a}, \mathrm{c}}$

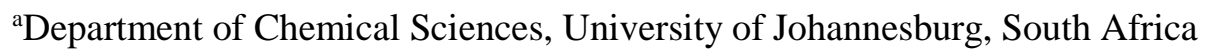 \\ ${ }^{\mathrm{b}}$ Institut Européen des Membranes, IEM, UMR 5635, Univ Montpellier, CNRS, ENSCM, Montpellier, \\ France ${ }^{\mathrm{b} C e n t r e}$ for Nanomaterials Science Research, University of Johannesburg, South Africa
}

\begin{abstract}
In this study, cathodic electro-Fenton (EF) and anodic photoelectrochemical (PEC) oxidation were coupled into a single electrochemical advanced oxidation system for the mineralisation of paracetamol. Thermally treated carbon felt and FTO-BiVO $4 / \mathrm{BiOI}$ were used as cathode and anode respectively. The result revealed that the thermal treatment of commercial carbon felt improved its degradation performance. EF degradation of paracetamol at the modified carbon felt cathode yielded $71 \%$ total organic carbon (TOC) removal which was about three times higher than the TOC removal at raw carbon felt after $4 \mathrm{~h}$ with a current density of $20 \mathrm{mAcm}^{-2}$. By coupling the EF degradation process with PEC oxidation, the complete removal of paracetamol was achieved within $2 \mathrm{~h}$ and a higher mineralisation of $92 \%$ TOC removal after $4 \mathrm{~h}$ with a lower applied current density of $10 \mathrm{mAcm}^{-2}$ was also recorded. The specific energy consumption of the EF/PEC process was about $64 \%$ lower than the energy consumption of EF process alone. The radical trapping experiments revealed that hydroxyl radicals, which were generated through PEC oxidation and EF reactions, played predominant roles in the degradation process. The coupled system is also environmentally friendly because the treated aqueous solution exhibited reduced toxicity in comparison with the untreated solution with about $1 \%$ inhibition of Vibrio fisheri. The findings from this research established the feasibility of achieving remarkable mineralisation of emerging organic pollutants through a degradation system consisting of EF and PEC oxidation at a lower energy cost within a short period of time. Therefore, the system has a greater potential for industrial applications.
\end{abstract}


Keywords: wastewater treatment; Electro-Fenton; Photoelectrochemical oxidation; paracetamol; photoanode

\subsection{Introduction}

Availability of clean water remains a major concern in recent years owing to the rise in water pollution rate. While improper disposal of household effluents and some natural phenomena contribute to water pollution, rapid industrialization is mostly responsible for the recent increase in water pollution as many effluents from the industries are not often properly treated before being discharge into water bodies [1,2]. Such effluents often contain complex matrix of recalcitrant organic compound which can be harmful to human, animals and aquatic lives at low and elevated concentrations [3]. Due to the complexity and recalcitrant nature of the pollutants, the effectiveness of conventional wastewater treatment methods is on the decline. In fact, residual amounts of organic pollutants have been reportedly found in treated water from wastewater treatment plants [4]. In the quest to find methods suitable for total removal of recalcitrant organic pollutants, advanced oxidations processes (AOPs) have received much attention. In AOPs, oxidants, particularly in situ generated hydroxyl radicals, attack organics non-selectively. Unlike conventional water treatment methods, total mineralisation of organics is attainable with no generation of secondary pollutants [5]. Common examples of AOPs include photocatalysis [6], UV photolysis [7], Fenton oxidation [8], UV ozonation [9] and photoelectrocatalytic oxidation [10].

Among the existing AOPs, Fenton oxidation has widely been applied due to its simple operation, relatively low cost and high degradation efficiency [11]. In Fenton oxidation, hydroxyl radicals which breakdown organic molecules, are produced from spontaneous reactions of iron catalyst and hydrogen peroxide $\left(\mathrm{H}_{2} \mathrm{O}_{2}\right)$. When hydrogen peroxides are continuously electrochemically generated on-site at the cathode by the reduction oxygen at the cathode the process is termed electro-Fenton (EF) [12]. Electro-Fenton has been successfully applied for wastewater treatment

to mineralise dyes, pharmaceuticals and other persistent pollutants [13-16]. Selection of appropriate cathodic material is a crucial factor in the construction of an efficient EF reactor and remarkable success has been reported with the use of carbon-based materials such as carbon sponge [17], carbon felt [18] and carbon nanofibers [19]. Furthermore, these materials, especially 
carbon felts, have been subjected to different modification in order to enhance the production of electrogenerated hydrogen peroxide by increasing the electroactive surface area and the hydrophilicity of the carbon material [16,20]. However, just like other AOPs, total mineralisation of organics is not often reported or only achieved after a relatively long period with very high energy consumption in the EF process.

An approach to enhance the efficiency of AOPs towards water treatment applications is the coupling of two compatible AOP processes. The underlying idea behind this coupling is to increase the production of radicals which may lead to improved degradation performance. In this regard, anodic oxidation (AO) has been incorporated into an EF process. For instance, asdemonstrated by Ganiyu et al. [21], 96\% total organic carbon (TOC) removal of $\beta$-blocker propanol was attained by combining EF with AO through the use of sub-stochiometric titanium oxide $\left(\mathrm{Ti}_{4} \mathrm{O}_{7}\right)$ as anode while EF alone yielded a lowered $89 \%$ TOC removal. In a report by Xuet al., unlike $52 \%$ TOC removal of 2,4-dichlorophenoxyacetic acid achieved with EF, 78\% TOC removal was recorded by coupling AO with EF using boron doped diamond (anode) and carbon black modified graphite felt (cathode) [22].

Photoelectrochemical oxidation (PEC) has been shown to be an improved version of AO because in PEC, both light and electric energy are used to generate reactive oxygen species in reaction medium which oxidize organics [23-25]. The anode in PEC often consist of a semiconductor photocatalyst capable of absorbing photons preferably in the visible light region to produce electron - hole pairs. The holes can serve as oxidants or further react with water molecules to generate hydroxyl radicals $[25,26]$. The synergistic effect between light and electric energy accounts for higher performance of PEC degradation over AO. PEC with visible light active semiconductors have been successfully applied for the mineralization of recalcitrant organic pollutants such as dyes and pharmaceuticals [27-31]. However, to the best of our knowledge, enhancement of EF degradation by combining it with PEC oxidation has not been reported in the literatures.

Herein, we report for the first time, the degradation of organic molecules in a coupled system of PEC and EF processes. The focus of the research is to demonstrate the feasibility of coupling anodic PEC oxidation with cathodic EF degradation for enhance mineralization of organic micropollutants. The anode used in this study is bismuth vanadate - bismuth oxyiodide 
electrodeposited on fluorine doped tin oxide glass (FTO-BiVO4/BiOI). As reported in our earlier study [32], the material offers impressive PEC degradation ability and good stability because of the $\mathrm{p}$-n heterojunction formed. The cathode for the EF process is a modified carbon felt with good porosity and hydrophilicity which was prepared through a simple thermal treatment. Paracetamol, a commonly found pharmaceutical in the environment, which can be toxic to aquatic organisms [33], was selected as target organic pollutants. Chromatographic technique and total organic carbon analysis were used to assess the degree of removal and mineralization. The role of reactive oxygen species in the mineralization was also established through trapping experiments. The toxicity assessment of the treated aqueous solution using a marine bacterium was also carried out.

\subsection{Experimental methods}

\subsection{Materials}

Paracetamol (acetaminophen), sodium sulphate (anhydrous, $\geq 99 \%$ ). iron (II) sulphate heptahydrate (99\%), absolute acetone (99\%), absolute ethanol (99\%), Potassium hexacyanoferrate ( $\geq 99 \%$ ) and potassium nitrate ( $\geq 99 \%$ ) were obtained from Sigma-Aldrich(Germany). Carbon felt was purchased from Alfa Aesar, Thermofisher (Germany)

\subsection{Preparation of Electrodes}

The cathodic material was prepared through thermal modification of commercial carbon felt $(5 \mathrm{~cm}$ x $11 \mathrm{~cm}$ x $1.67 \mathrm{~cm}$ ) following the procedure previously described by Le et al. [34]. Briefly, raw carbon felt (CF) was cleaned through ultrasonication for $1 \mathrm{~h}$ each in acetone and ethanol, then rinsed thoroughly with deionized water and dried at $60{ }^{\circ} \mathrm{C}$ for $24 \mathrm{~h}$. The cleaned carbon felt was subjected to thermal treatment at a temperature of $1000{ }^{\circ} \mathrm{C}$ for $2 \mathrm{~h}$ in a tubular furnace (Vecstar Ltd) under the continuous flow of a mixture of nitrogen and oxygen (1\% oxygen) at a flow rate of $200 \mathrm{~mL} / \mathrm{min}$. The obtained thermally treated carbon felt material was denoted T-CF. The photoanode employed in this study is $\mathrm{FTO}-\mathrm{BiVO}_{4} / \mathrm{BiOI}$ and the preparation methodology and full characterization has been reported elswhere [32]. 


\subsection{Material Characterisation}

Scanning electron microscopy (Hitachi S4800, Japan) was used to examine the change in the surface morphology of the modified carbon felt as compared to the raw carbon felt. The electroactive surface areas of the materials were calculated through cyclic voltammetry experiments on Autolab PGSTAT204 (Netherlands) potentiostat/galvanostat with three-electrode configuration. Raw carbon felt and thermal treated carbon felt served as the working electrodes while $\mathrm{Ag} / \mathrm{AgCl}(3.0 \mathrm{M} \mathrm{KCl})$ and platinum foil were used as the reference and working electrodes. The voltammograms were recorded in the solution of $10 \mathrm{mM} \mathrm{K} 3\left[\mathrm{Fe}(\mathrm{CN})_{6}\right]$ prepared in $0.1 \mathrm{M} \mathrm{KCl}$.

\subsection{Mmineralization of paracetamol}

The experiment setup earlier described by Le et al. [34] was adopted for the electro-Fenton mineralization of paracetamol in aqueous solution. A $100 \mathrm{~mL}$ capacity undivided two-electrodes cell was used while a power source (CNB Electronique, EU) was used to control the applied current within the cell. The thermally modified carbon felt $\left(2 \mathrm{~cm}^{2}\right)$ was employed as the working electrode (cathode) and the anode was platinum mesh. The distance between the electrodes was kept constant at $3 \mathrm{~cm}$. The working solution was made up of $50 \mathrm{~mL}$ aqueous solution of $0.1 \mathrm{mM}$ paracetamol prepared in a solution of $50 \mathrm{mM} \mathrm{Na}_{2} \mathrm{SO}_{4}$ (supporting electrolyte) in the presence of $0.2 \mathrm{mM} \mathrm{FeSO}_{4} .7 \mathrm{H}_{2} \mathrm{O}$ (catalyst). The $\mathrm{pH}$ of the solution was adjusted to 3 using $1 \mathrm{M} \mathrm{H}_{2} \mathrm{SO}_{4}$. The solution was continuously saturated with $\mathrm{O}_{2}$ during the electrolysis process by bubbling compressed air into the reactor through a frit, starting $10 \mathrm{~min}$ before the reaction to achieved constant $\mathrm{O}_{2}$ saturation. Aliquots were collected at specific time intervals for paracetamol concentration and total organic carbon contents.

The coupling of electro-Fenton process with photoelectrocatalytic degradation process was carried out in the reactor described above by replacing the platinum mesh with FTO-BiVO $/ \mathrm{BiOI}\left(2 \mathrm{~cm}^{2}\right)$ photoanode. A $150 \mathrm{~W}$ linear halogen lamp (in the range of $420-600 \mathrm{~nm}$ ) was used asthe light source and the photoanode was irradiated from the rear with a distance of $20 \mathrm{~cm}$ from the lamp. Photoelectrocatalytic degradation of paracetamol was also carried out using a similar setup without the addition of catalyst $\left(\mathrm{FeSO}_{4} \cdot 7 \mathrm{H}_{2} \mathrm{O}\right)$ with $\mathrm{FTO}-\mathrm{BiVO}_{4} / \mathrm{BiOI}$ and platinum mesh 
functioning as working electrode (photoanode) and cathode respectively. Sample aliquots were also taken for analyses.

\subsection{Analytical Procedures}

Decrease in the total organic carbon (TOC) was used to assess the extent of mineralization of the paracetamol molecules by measuring the TOC contents of the initial and aliquots solutions on a TOC-L CSH/CSN Shimadzu (Japan) analyzer. Calibration curves for total carbon (TC) and inorganic carbon (IC) analysis were built up by automatic dilution of standards solutions of TOC (potassium hydrogenophtalate) and IC (sodium hydrogen carbonate). The TOC data obtained were then used to estimate the mineralization current efficiency (MCE, \%) of the solutions over a specified time $\mathrm{t}(\mathrm{h})$ using equation 1 [35].

$$
\operatorname{MCE}(\%)=\frac{n F V_{s} \Delta(T O C)_{\exp }}{4.32 \times 10^{7} \mathrm{mIT}} \cdot 100
$$

The number of electrons consumed in the mineralization of each paracetamol molecule is represented by $\mathrm{n}, \mathrm{F}$ is the Faraday constant $\left(96485 \mathrm{C} \mathrm{mol}^{-1}\right)$, Vs is the solution volume (L), $\Delta$ (TOC)exp is the experimental TOC decay $\left(\mathrm{mg} \mathrm{L}^{-1}\right), 4.32 \times 10^{7}$ is a conversion factor (3600 s

$\mathrm{h}^{-1} \times 12000 \mathrm{mg}$ carbon $\left.\mathrm{mol}^{-1}\right), \mathrm{m}$ is the number of carbon atoms in each paracetamol molecule ( 8 atoms), the current passing through the system in time $t$ is denoted as I. The number of electrons (n) consumed for mineralization was 34 for the PCM molecule, according to the stoichiometry of the reaction in equation 2 [36]:

$$
\mathrm{C}_{8} \mathrm{H}_{9} \mathrm{NO}_{2}+14 \mathrm{H}_{2} \mathrm{O} \rightarrow 8 \mathrm{CO}_{2}+\mathrm{NH}_{4}^{+}+33 \mathrm{H}^{+}+34 e^{-}
$$

Additionally, the specific energy consumption (EC) per unit TOC mass $\left(\mathrm{kWh}^{-1} \mathrm{TOC}\right)$ was also calculated using equation 3 .

$$
E C_{T O C}=\frac{V I t}{(\triangle T O C)_{e x p} V_{s}}
$$

Where the average cell voltage $(\mathrm{V})$, applied current $(\mathrm{A})$, reaction time $(\mathrm{h})$ and solution volume (L) are denoted as V, I, t and Vs respectively 
The concentration decay of paracetamol molecules was estimated through high performance liquid chromatography - mass spectrometry (HPLC-MS). HPLC-MS was carried out with a Waters 2695 pump, an auto sampler with $20 \mu \mathrm{L}$ loop, a Waters 2695 separation module (HPLC), and a Waters Micromass (Wythenshawe, Manchester, UK) Quattro Micro mass spectrometer equipped with ESI (Electrospray Ionization). HPLC was performed on a Waters - Xselect HSS T3 column at a column temperature of $25^{\circ} \mathrm{C}$. The mobile phase was a Buffer A (HPLC grade water $+0.1 \%$ formic acid) and Buffer B (HPLC grade acetonitrile $+0.05 \%$ formic acid). The flow-rate was constant at 0.25 $\mathrm{mLmin}^{-1}$, with a split of $20 \%$ to the mass spectrometer. The triple quadrupole MS was operated in selected-ion-recording (SIR) mode with compounds being ionized in the negative electrospray ionization mode. To achieve the best sensitivity, the MS was adjusted to facilitate the ionization process. The detection conditions were: capillary potential $3.5 \mathrm{kV}$, cone potential $30 \mathrm{~V}$, source temperature $120{ }^{\circ} \mathrm{C}$, desolvatation temperature $450{ }^{\circ} \mathrm{C}$, cone gas flow $50 \mathrm{Lh}^{-1}$, and desolvatation gas flow $450 \mathrm{Lh}^{-1}$. Nitrogen was the nebulizer gas.

\subsection{Results and discussion}

\subsection{Morphological characterization of thermal modified carbon felt}

The SEM images of raw carbon felt and thermal modified carbon felt were obtained andpresented in Figure $1 \mathrm{a}$ and $\mathrm{b}$. The thermal treatment of the carbon felt at $1000{ }^{\circ} \mathrm{C}$ for $1 \mathrm{~h}$ under the continuous flow of nitrogen (containing 1\% oxygen) introduced some degree of roughness and porosity into the carbon felt. This roughness suggests an increase in surface area and thiswas further confirmed through cyclic voltammetry in ferrocyanide solution. The voltammogramsof the two materials exhibited the typical curve of a reversible redox reaction but the thermal treated carbon felt show a higher current response than the raw carbon felt (Figure 1c). This increase is attributed to increase in the surface area of the T-CF resulting in higher electron mobility and mass transfer between the cathode and the electrolyte. The electroactive surface areas of CF and T-CF were subsequently calculated using the Randles-Sevcik equation 4 [37]:

$$
\text { ip }=k n^{3 / 2} A D^{1 / 2} v^{1 / 2} C
$$

Where $\mathrm{A}$ is the electroactive surface area, ip is the peak current, $\mathrm{C}$ is the redox probe concentration $(10 \mathrm{mM}), \mathrm{D}$ is the diffusion coefficient $\left(7.6 \times 10^{-6}\right.$ for ferrocyanide), $\mathrm{v}$ is the scan 
rate and $\mathrm{k}$ is a constant $\left(2.69 \times 10^{5}\right)$. Accordingly, the electroactive surface areas of raw carbon felt and thermally treated carbon felt were $49.25 \mathrm{~cm}^{2} \mathrm{~g}^{-1}$ and $502.64 \mathrm{~cm}^{2} \mathrm{~g}^{-1}$ respectively. This marked increase confirms the effect of the thermal treatment process.

(a)

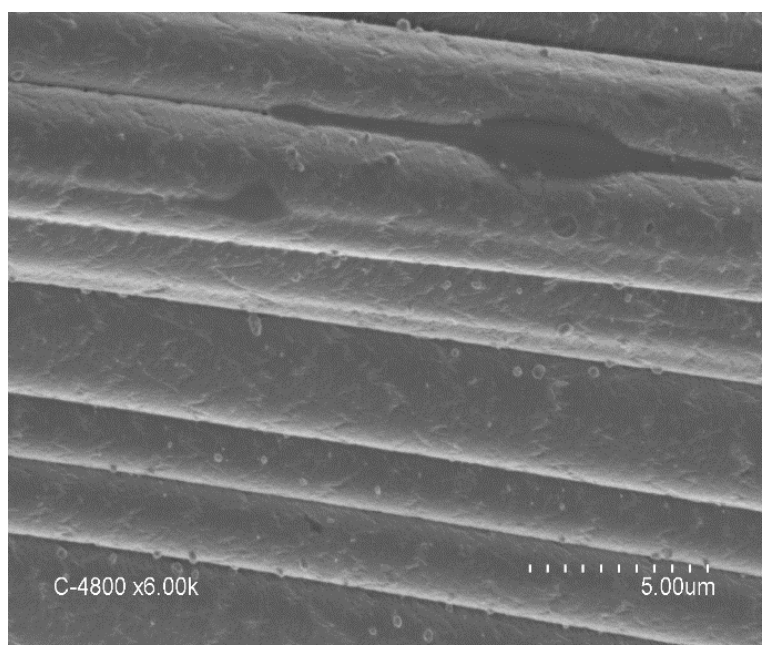

(b)

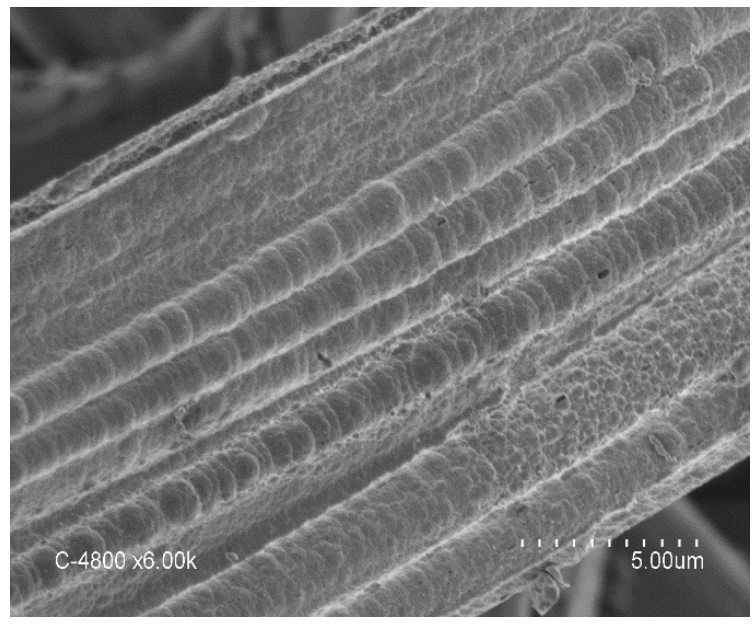




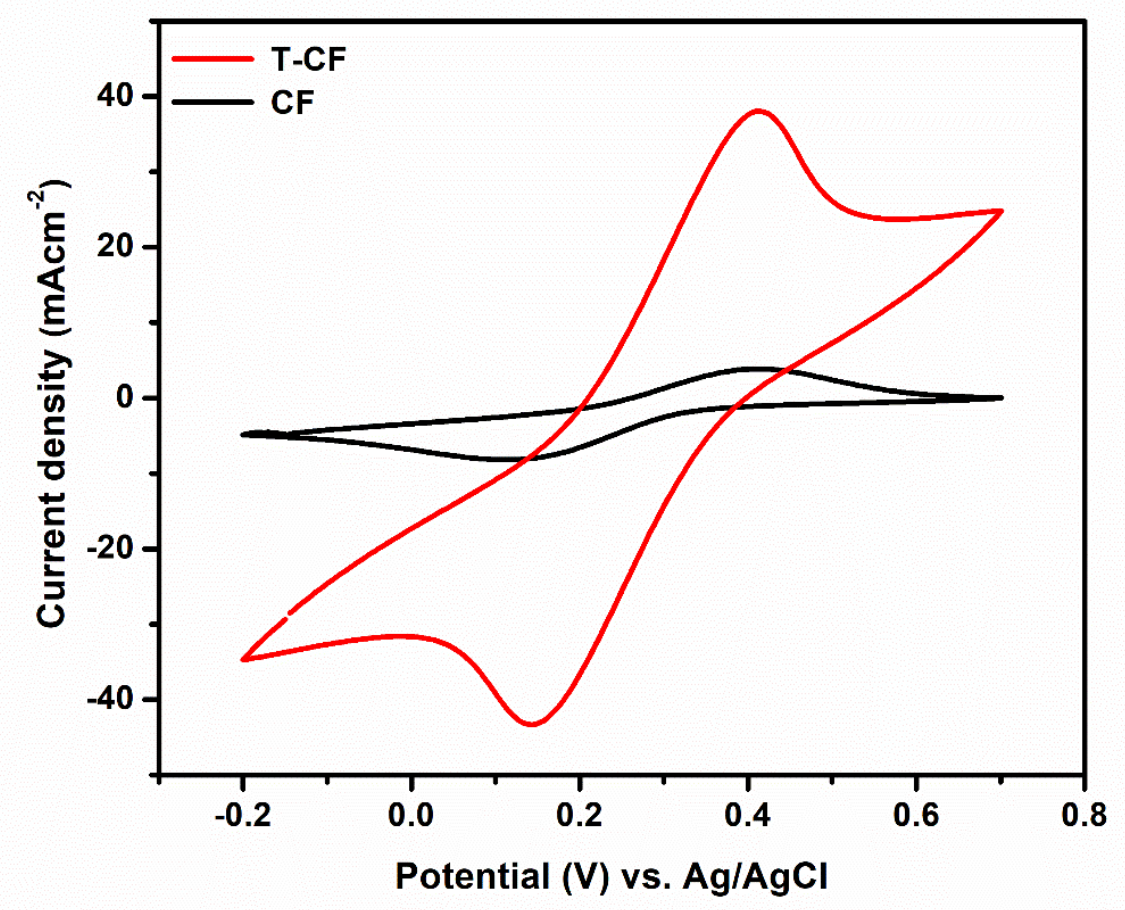

(c)

Figure 1: SEM images of (a) raw carbon felt (CF); (b) thermally treated carbon felt (T-CF); (c) cyclic voltammograms of raw carbon felt and thermal treated carbon felt in $10 \mathrm{mM} \mathrm{K}_{3}\left[\mathrm{Fe}(\mathrm{CN})_{6}\right]$ at a scan rate of $7 \mathrm{mVs}^{-1}$

\subsection{Electro-Fenton mineralization of paracetamol}

Both the raw CF and the T-CF were applied as working electrode (cathode) for the abatement of $0.1 \mathrm{mM}$ paracetamol in acidic aqueous solution through electro-Fenton reaction and the results are presented in Figure 2a and $\mathrm{b}$. The percentage TOC removal achieved with the use of T-CF was $71 \%$ after $4 \mathrm{~h}$ while $27 \%$ was recorded with the raw CF (Figure 2a). Furthermore, a higher mineralization current efficiency (MCE) was observed with the application of T-CF (Figure $2 b$ ). The higher TOC and MCE achieved with T-CF can be rightly attributed to the thermal treatment which increased electroactive surface area, hydrophilicity and porosity over the raw CF [34]. It is also worth noting that the thermal treatment improved the conductivity of the T-CF and this was clearly seen during the experiments as the observed cell potential corresponding to $-20 \mathrm{mAcm}^{-2}$ $(40 \mathrm{~mA})$ was $4.3 \mathrm{~V}$ with $\mathrm{T}-\mathrm{CF}$ while that of raw $\mathrm{CF}$ was $5.8 \mathrm{~V}$. The hydrophilicity and porosity 
of the T-CF played the role of facilitating the circulation of dissolved oxygen within the electrolyte solution onto the active sites of the cathode which resulted in the generation of the hydroxyl radicals, powerful oxidants, which attacked the paracetamol molecules. This reaction is well described in equations 5 and 6 [38];

$$
\begin{aligned}
& \mathrm{O}_{2}+2 \mathrm{H}^{+}+2 e^{-} \rightarrow \mathrm{H}_{2} \mathrm{O}_{2} \\
& \mathrm{Fe}^{2+}+\mathrm{H}_{2} \mathrm{O}_{2}+\mathrm{H}^{+} \rightarrow \mathrm{Fe}^{3+}+\cdot \mathrm{OH}+\mathrm{H}_{2} \mathrm{O}
\end{aligned}
$$

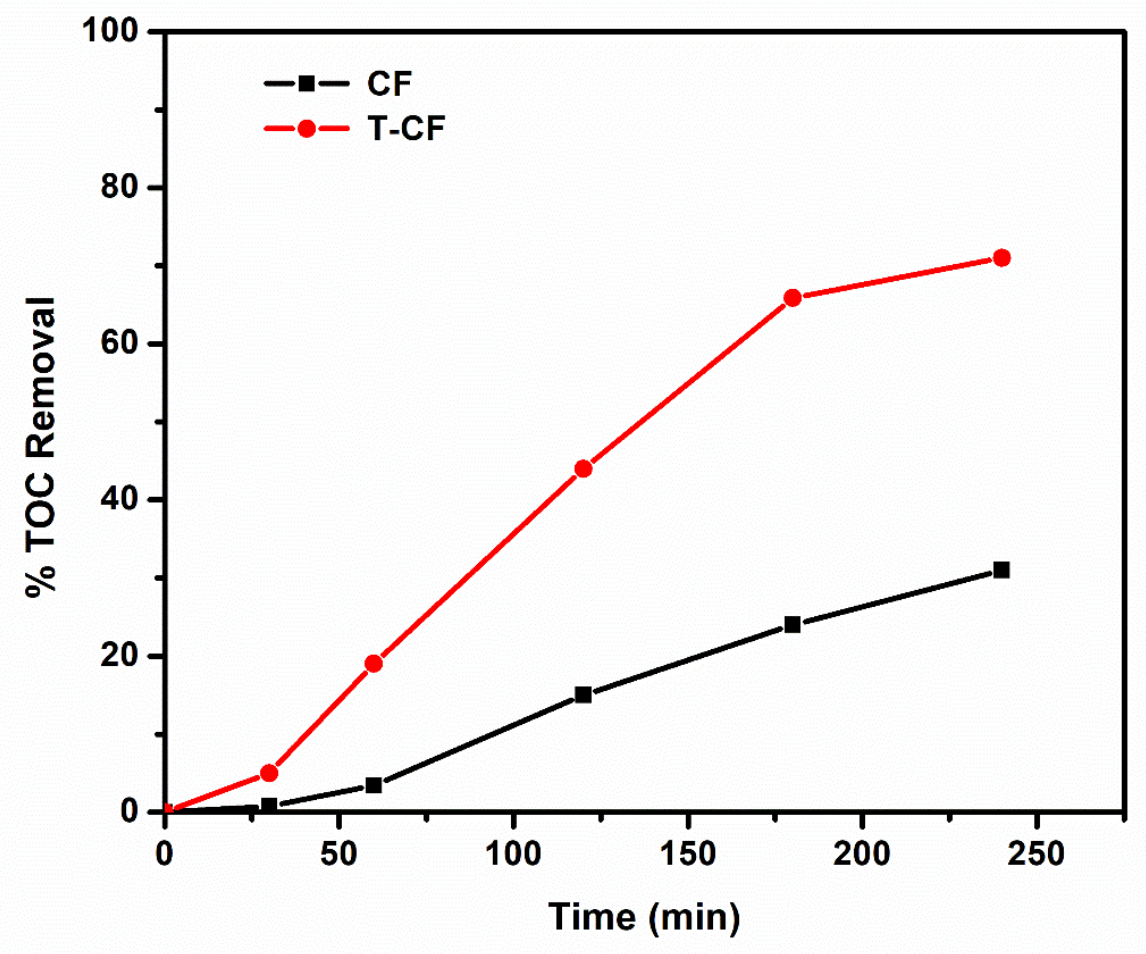

(a) 


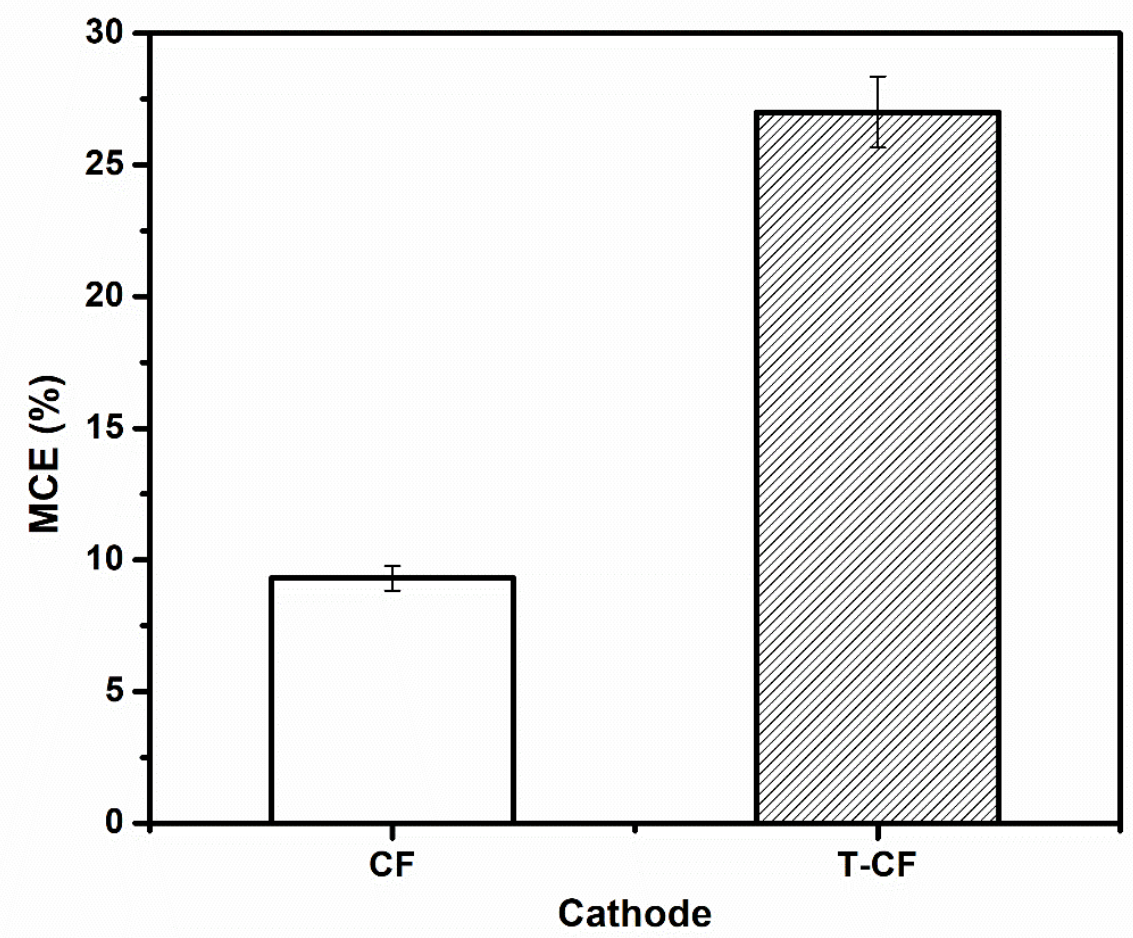

(b)

Figure 2: (a) Percentage TOC removal of paracetamol through electro-Fenton process using raw carbon felt and thermal treated carbon felt; (b) Corresponding mineralization current efficiency after 4 h. (0.1 mM paracetamol; $\left.50 \mathrm{mM} \mathrm{Na}_{2} \mathrm{SO}_{4} ; 20 \mathrm{mAcm}{ }^{-2} ; \mathrm{pH} 3\right)$

\subsection{Photoelectrocatalytic degradation of paracetamol}

Aqueous solution containing $0.1 \mathrm{mM}$ paracetamol in the presence of $50 \mathrm{mM} \mathrm{Na}_{2} \mathrm{SO}_{4}$ was also subjected to photoelectrocatalytic degradation (PEC) on a $\mathrm{FTO}-\mathrm{BiVO}_{4} / \mathrm{BiOI}$ anode. The results are presented in Figure $3(\mathrm{a}-\mathrm{c})$. The percentage removal of $98 \%$ was obtained after $2 \mathrm{~h}$ and thereafter total removal of paracetamol was observed as recorded with liquid chromatography. When the experiment was carried out in the absence of visible light with only an applied current of $10 \mathrm{mAcm}^{-2}$, the electrocatalytic degradation (EC) achieved $61 \%$ percentage removal of paracetamol after $2 \mathrm{~h}$; while the photocatalysis experiment (PC) recorded the lowest percentage removal of $13 \%$ for paracetamol after $2 \mathrm{~h}$. The highest percentage removal achieved with PEC process can be attributed to the synergistic effect of combining both light and electrical energy. 
When the photoanode is irradiated, it absorbs photons and photo excited electron - hole pairs are generated. The holes generated can either oxidize directly the paracetamol molecules or react with water to produces stronger oxidants of hydroxyl radicals which then attack the paracetamol molecules. Application of current helps in driving away electrons from the photoanode thereby inhibiting the spontaneous recombination of electrons and holes which enables more oxidants to be available for the breaking down of the paracetamol molecules in addition to the oxidants generated through the anodic oxidation of water molecules [24,39]. This is summarized in equations $7-12$.

$$
\begin{aligned}
& h v+\mathrm{BiVO}_{4} / \mathrm{BiOI} \rightarrow \mathrm{BiVO}_{4} / \mathrm{BiOI}\left(h^{+}+e^{-}\right) \\
& e^{-}+\mathrm{O}_{2} \rightarrow \cdot \mathrm{O}^{-} \\
& h^{+}+\mathrm{H}_{2} \mathrm{O} \rightarrow \cdot \mathrm{OH}+\mathrm{H}^{+} \\
& \cdot \mathrm{OH}+\text { paracetamol } \rightarrow \mathrm{CO}_{2}+\mathrm{H}_{2} \mathrm{O} \\
& \cdot \mathrm{O}_{7}^{-}+\text {paracetamol } \rightarrow \mathrm{CO}_{2}+\mathrm{H}_{2} \mathrm{O} \\
& h^{+}+\text {paracetamol } \rightarrow \mathrm{CO}_{2}+\mathrm{H}_{2} \mathrm{O}
\end{aligned}
$$

It is interesting to note that the total removal of paracetamol as recorded with chromatographic technique did not result in total mineralization of paracetamol molecules as recorded with TOC analysis. Specifically, the percentage TOC removal achieved after $4 \mathrm{~h}$ through PEC process was $59 \%$ while with EC was $40 \%$. The difference reveals that though all paracetamol molecules were completely gone after $3 \mathrm{~h}$, organic molecules were still in the solutions suggesting that the paracetamol molecules disintegrated into smaller chain hydrocarbons as previously reported [40].

Additionally, the effect of current density on the PEC mineralization was also studied within 5 $20 \mathrm{mAcm}^{-2}$ current density range. The percentage removal of paracetamol increased appreciably as the current density increased from $5 \mathrm{mAcm}^{-2}$ to $10 \mathrm{mAcm}^{-2}$ (Figure 3c). The increase in photocurrent aided in driving away electrons from the photoanode thereby promoting charge separation within the semiconductors [31]. With the application of $15 \mathrm{mAcm}^{-2}$, the increase in percentage removal was not so significant whereas the application of $20 \mathrm{mAcm}^{-2}$ affected the stability of the semiconducting materials on the FTO glass within $40 \mathrm{~min}$ and this resulted in 
pronounced decrease in the percentage removal. These results suggest that increase in current density may not always lead to improved degradation. A current density of $10 \mathrm{mAcm}^{-2}$ was selected as the optimum and was applied for subsequent experiments.

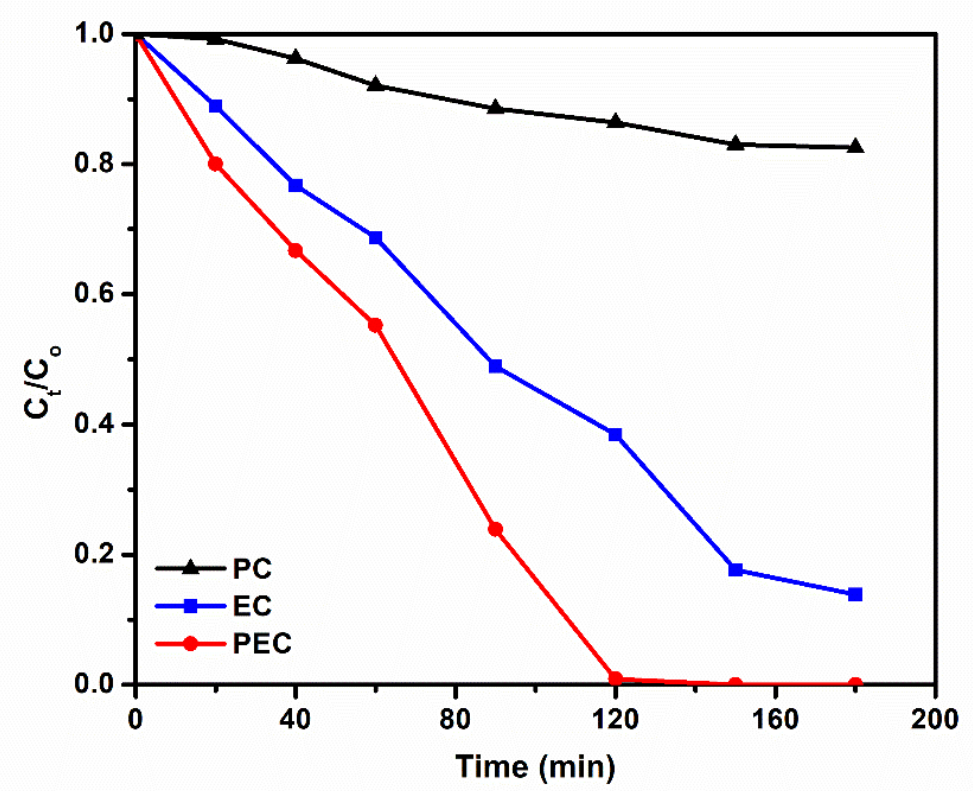

(a)

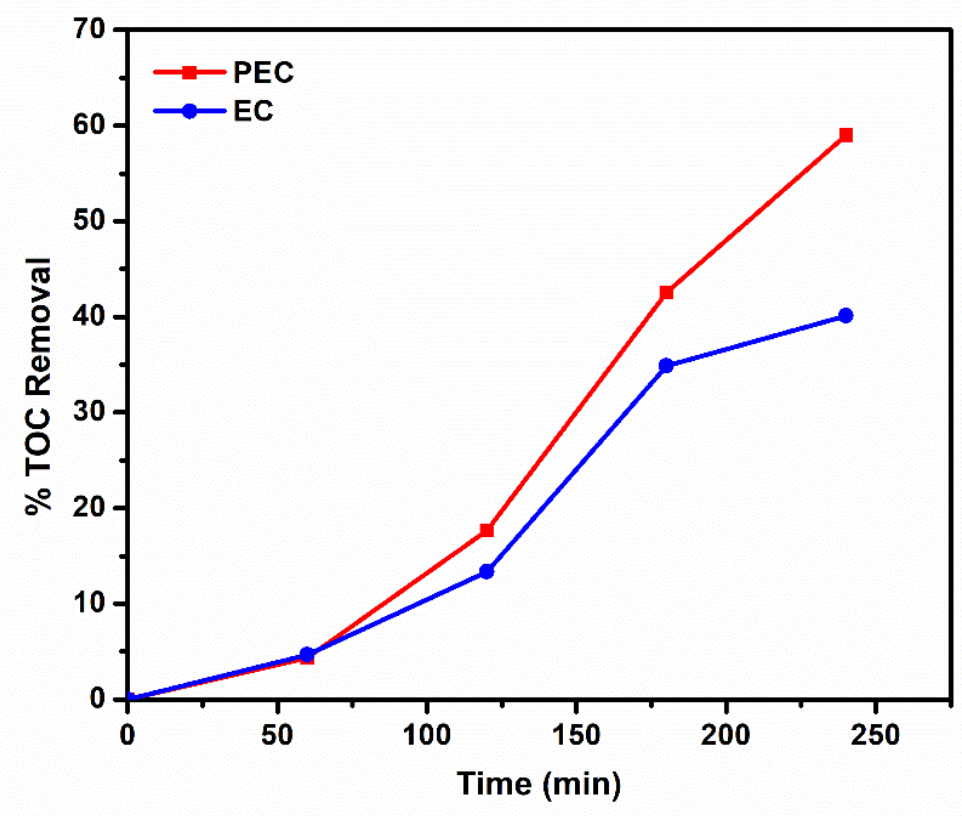

(b) 


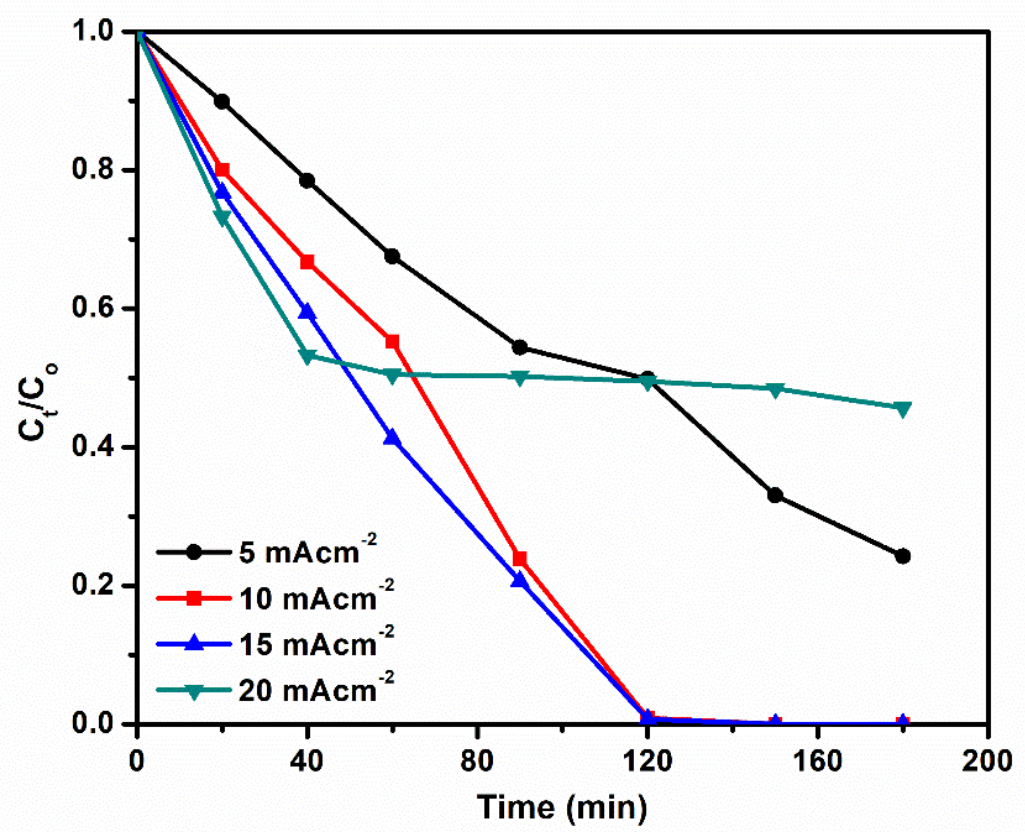

(c)

Figure 3: (a) Normalized concentration decay plot for photocatalytic, electrocatalytic and photoelectrocatalytic degradation of paracetamol and (b) corresponding percentage TOC removal; (c) Effect of current densities on the PEC degradation of paracetamol on FTO- $\mathrm{BiVO}_{4} / \mathrm{BiOI}$. (pH 3; $0.1 \mathrm{mM}$ paracetamol)

\subsection{Coupling of electro-Fenton with PEC process for mineralization of paracetamol}

The results for the mineralization of $0.1 \mathrm{mM}$ paracetamol solutions in a combined system of EF and PEC using T-CF and FTO-BiVO $/$ /BiOI as cathode and photoanode respectively are presented in Figure 4a. The experiment was performed with a current density of $10 \mathrm{mAcm}^{-2}$ (EF/PEC 10) based on the unimpressive performance (32\% TOC removal) of the photoanode during PEC degradation at $20 \mathrm{mAcm}^{-2}$ (PEC 20). The coupled process resulted in $92 \%$ TOC removal of paracetamol after $4 \mathrm{~h}$ which was remarkably higher than the values achieved with individual processes of EF (28\%) and PEC (59\%) at $10 \mathrm{mAcm}^{-2}$ (EF 10 and PEC 10). The improved performance noted in the coupled process can rightly be attributed to the fact that 
spontaneous degradation of the paracetamol molecules was taking place simultaneously at both anode and cathode which therefore proved that the two processes are quite compatible for enhanced mineralization of organic pollutants. Additionally, the superiority of the coupled process is also evident in its lower energy consumption because the EF process alone, even at higher current density of $20 \mathrm{mAcm}^{-2}$ (EF 20), resulted in $71 \%$ TOC removal which was still lower than the percentage TOC removal achieved with the coupled process at $10 \mathrm{mAcm}^{-2}$.

The energy consumptions per unit TOC mass using $10 \mathrm{mAcm}^{-2}$ were $1.943,1.031$ and $0.696 \mathrm{kWg}^{-}$ ${ }^{1}$ TOC for EF, PEC and EF/PEC respectively. A calculated 64\% reduction in energy consumption further suggests the cost effectiveness of the coupled process. In order to confirm the specific role of light, the coupled process was also applied in the absence of light (EF/EC 10) and the percentage TOC removal decreased to $73 \%$. This indicated that the application of light facilitated the production of more oxidants through the photogenerated electron-hole pairs in the photoanode resulting in enhanced mineralization.

Obviously, in the coupled system, a number of oxidants from both the anode and cathode are responsible for the mineralization of paracetamol molecules. Trapping experiments were therefore conducted to gain an insight into the specific roles of hydroxyl radicals, holes and superoxide radicals in the mineralization of paracetamol using combined EF-PEC. Isopropanol (IPA), pbenzoquinone ( $\mathrm{p}-\mathrm{BQ})$ and ethylenediamine tetraacetate (EDTA) were added to the reaction medium to suppress the effect of hydroxyl radicals, superoxide radicals and holesrespectively [41,42]. As shown in Figure 4b, the percentage TOC removal dropped drastically to $37 \%$ with the additional of IPA while $86 \%$ and $62 \%$ TOC removal were still recorded with the additional of pBQ and EDTA respectively. This reveals that both photogenerated holes and superoxide radicals which were majorly produced by the photoanode play a lesser role in the mineralization process. However, hydroxyl radicals plays predominant role in the mineralization process and this can be attributed to the fact that hydroxyl radicals are the major oxidants acting in the electro-Fenton process originating through the cathode and more hydroxyl radicals becameavailable in the reaction medium when $\mathrm{FTO}_{-} \mathrm{BiVO}_{4} / \mathrm{BiOI}$ photoanode was used as the anode because photogenerated holes from the anode also generate hydroxyl radicals when reacted with water. 
The degradation pathway of paracetamol molecules has been previously established by researchers and it has been confirmed that some intermediate products during the degradation may be even more harmful than the paracetamol molecules in water environment $[43,44]$.Therefore, the toxicity of the treated solution was evaluated by measuring the effect on the luminescence of Vibrio fisheri, a marine bacterium. As shown in Figure 4c, the acute toxicity of the treated solution increased substantially after a treatment time $1 \mathrm{~h}$ as observed in the percentage inhibition after $5 \mathrm{~min}(21 \%)$ and $15 \mathrm{~min}$ (40\%) contact time with $V$. fisheri. This revealed that toxic intermediate products were formed during the initial stage of the mineralization experiments. This is consistent with earlier reports which revealed that toxic compounds such as p-benzoquinone, benzaldehyde and benzoic acid were formed during the earlier stage of paracetamol degradation $[33,43,45]$. However, the toxicity of the treated solution decreased with treatment time as the degradation continued; suggesting that the toxic intermediate products were further broken down. After $4 \mathrm{~h}$ treatment time the percentage inhibition was as low as $1 \%$ indicating that the treated water by the coupled $\mathrm{EF}$ and $\mathrm{PEC}$ process is relatively more environmentally friendly.

(a)

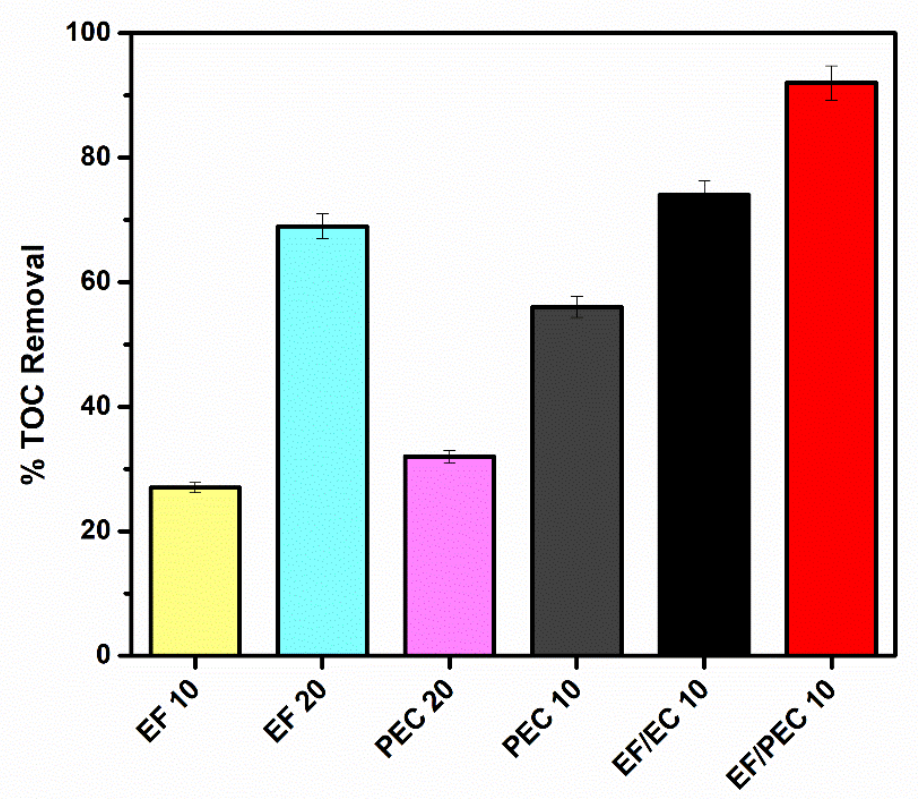




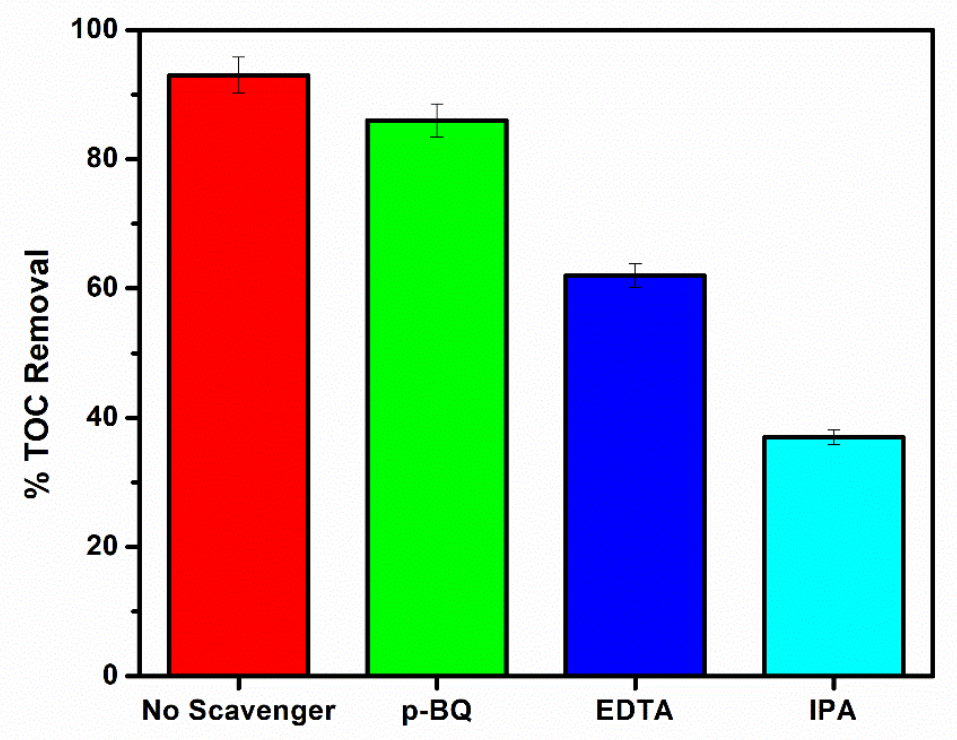

(b)

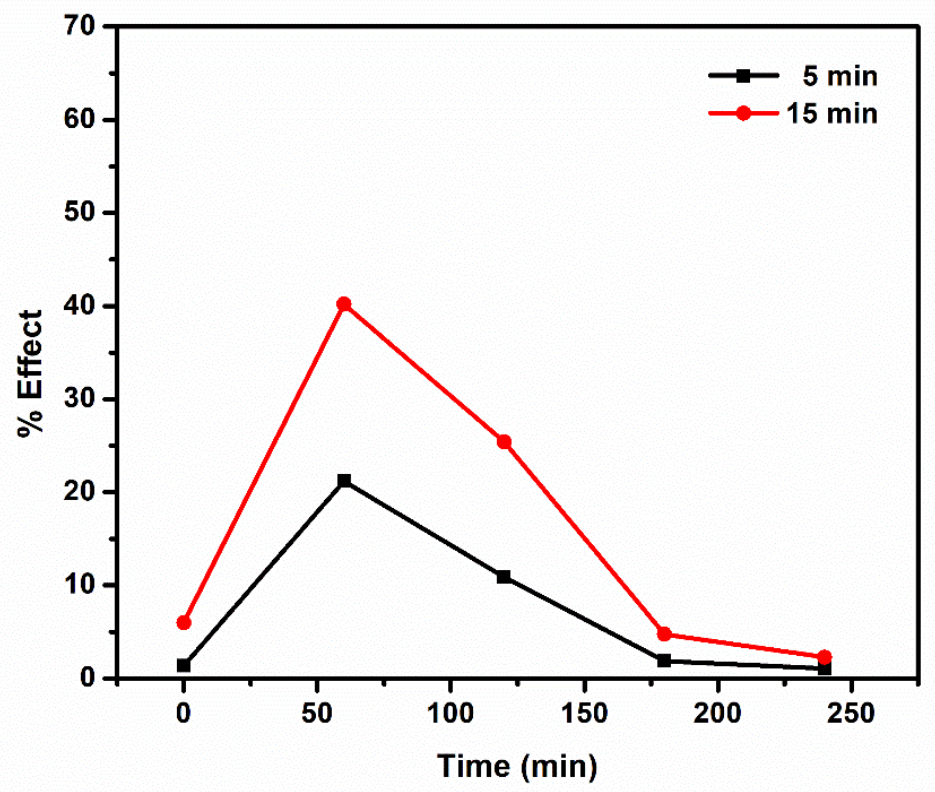

(c)

Figure 4: (a) Comparison between percentage TOC removal of paracetamol through coupled process of electro-Fenton/PEC degradation, electro-Fenton and PEC process at different current densities; (b) Trapping experiments and; (c) Toxicity assessment for the coupled process. 


\section{Conclusion}

In this study, we have successfully coupled two advanced oxidation processes - electro-Fenton (EF) and photoelectrochemical (PEC) oxidation - using thermal treated carbon felt (cathode) and FTO-BiVO $4 / \mathrm{BiOI}$ (photoanode). The porosity, electroactive surface and hydrophilicity of the thermal treated carbon felt were higher than the raw carbon felt. When the modified carbon felt was applied for mineralization of paracetamol through EF degradation in acidic medium, 71\% TOC removal was achieved which was almost three times higher than that of raw carbon felt after $4 \mathrm{~h}$ with a current density of $20 \mathrm{mAcm}^{-2}$. By coupling the EF degradation process with PEC oxidation, complete removal of paracetamol was achieved within $2 \mathrm{~h}$ and a higher mineralization of $92 \%$ TOC removal after $4 \mathrm{~h}$ with a low applied current density $\left(10 \mathrm{mAcm}^{-2}\right)$ was also recorded. Additionally, the energy consumption in the coupled process was $64 \%$ lower than in EF process alone which suggests that the application of coupled EF and PEC process is highly cost effective. The production of hydroxyl radicals was enhanced in the coupled process as the result showed that hydroxyl radicals played predominant role in the mineralization process. Furthermore, the treated aqueous solution has low toxicity showing about $1 \%$ percentage inhibition of Vibrio fisheri revealing that the coupled process is environmentally friendly. Findings from this research established the feasibility of achieving remarkable mineralization of emerging organic pollutants through a degradation process consisting of PEC oxidation and EF degradation with minimal energy consumption within a short period of time. For future work, considerations will be giving to scaling up the process and further modification of both anode and cathode materials achieve complete mineralization in shorter time.

\section{References}

[1] P. Amoatey, M.S. Baawain, Effects of pollution on freshwater aquatic organisms, Water Environ. Res. 91 (2019) 1272-1287. https://doi.org/10.1002/wer.1221.

[2] E. Hernández-Francisco, J. Peral, L.M. Blanco-Jerez, Removal of phenolic compounds from oil refinery wastewater by electrocoagulation and Fenton/photo-Fenton processes, J. Water Process Eng. 19 (2017) 96-100. https://doi.org/10.1016/j.jwpe.2017.07.010.

[3] A. Majumder, B. Gupta, A.K. Gupta, Pharmaceutically active compounds in aqueous 
environment: A status, toxicity and insights of remediation, Environ. Res. 176 (2019) 108542. https://doi.org/10.1016/j.envres.2019.108542.

[4] A.M. Deegan, B. Shaik, K. Nolan, K. Urell, M. Oelgemöller, J. Tobin, A. Morrissey, Treatment options for wastewater effluents from pharmaceutical companies, Int. J. Environ. Sci. Technol. 8 (2011) 649-666. https://doi.org/10.1007/BF03326250.

[5] I. Sirés, E. Brillas, Remediation of water pollution caused by pharmaceutical residues based on electrochemical separation and degradation technologies : A review, Environ. Int. 40 (2012) 212-229. https://doi.org/10.1016/j.envint.2011.07.012.

[6] A. Petala, A. Noe, Z. Frontistis, C. Drivas, S. Kennou, D. Mantzavinos, D.I. Kondarides, Synthesis and characterization of $\mathrm{CoOx} / \mathrm{BiVO} 4$ photocatalysts for the degradation of propyl paraben, J. Hazard. Mater. (2019) 52-60. https://doi.org/10.1016/j.jhazmat.2018.03.008.

[7] C.Y. Hu, Y.Z. Hou, Y.L. Lin, A.P. Li, Y.G. Deng, Degradation kinetics of diatrizoate during UV photolysis and UV/chlorination, Chem. Eng. J. 360 (2019) 1003-1010. https://doi.org/10.1016/j.cej.2018.09.189.

[8] F. Audino, L.O. Conte, A.V. Schenone, M. Pérez-Moya, M. Graells, O.M. Alfano, A kinetic study for the Fenton and photo-Fenton paracetamol degradation in an annular photoreactor, Environ. Sci. Pollut. Res. 26 (2019) 4312-4323. https://doi.org/10.1007/s11356-018-3098-4.

[9] Y. Wang, H. Li, P. Yi, H. Zhang, Degradation of clofibric acid by UV, O3 and UV/O3 processes: Performance comparison and degradation pathways, J. Hazard. Mater. 379 (2019) 120771. https://doi.org/10.1016/j.jhazmat.2019.120771.

[10] S. Garcia-Segura, E. Brillas, Applied photoelectrocatalysis on the degradation of organic pollutants in wastewaters, J. Photochem. Photobiol. C Photochem. Rev. 31 (2017) 1-35. https://doi.org/10.1016/j.jphotochemrev.2017.01.005.

[11] A. Mirzaei, Z. Chen, F. Haghighat, L. Yerushalmi, Removal of pharmaceuticals from water by homo/heterogonous Fenton-type processes - A review, Chemosphere. 174 (2017) 665-688. https://doi.org/10.1016/j.chemosphere.2017.02.019. 
[12] S.O. Ganiyu, M. Zhou, C.A. Martínez-Huitle, Heterogeneous electro-Fenton and photoelectro-Fenton processes: A critical review of fundamental principles and application for water/wastewater treatment, Appl. Catal. B Environ. 235 (2018) 103-129. https://doi.org/10.1016/j.apcatb.2018.04.044.

[13] H. Yang, M. Zhou, W. Yang, G. Ren, L. Ma, Rolling-made gas diffusion electrode with carbon nanotube for electro-Fenton degradation of acetylsalicylic acid, Chemosphere. 206 (2018) 439-446. https://doi.org/10.1016/j.chemosphere.2018.05.027.

[14] X. Mi, Y. Li, X. Ning, J. Jia, H. Wang, Y. Xia, Y. Sun, S. Zhan, Electro-Fenton degradation of ciprofloxacin with highly ordered mesoporous MnCo2O4-CF cathode: Enhanced redox capacity and accelerated electron transfer, Chem. Eng. J. 358 (2019) 299309. https://doi.org/10.1016/j.cej.2018.10.047.

[15] T.X. Huong Le, B. Alemán, J.J. Vilatela, M. Bechelany, M. Cretin, Enhanced ElectroFenton Mineralization of Acid Orange 7 Using a Carbon Nanotube Fiber-Based Cathode, Front. Mater. 5 (2018) 5-10. https://doi.org/10.3389/fmats.2018.00009.

[16] S.O. Ganiyu, T.X. Huong Le, M. Bechelany, N. Oturan, S. Papirio, G. Esposito, E. van Hullebusch, M. Cretin, M.A. Oturan, Electrochemical mineralization of sulfamethoxazole over wide $\mathrm{pH}$ range using Fe II Fe III LDH modified carbon felt cathode: Degradation pathway, toxicity and reusability of the modified cathode, Chem. Eng. J. 350 (2018) 844855. https://doi.org/10.1016/j.cej.2018.04.141.

[17] A. Özcan, Y. Şahin, A. Savaş Koparal, M.A. Oturan, Carbon sponge as a new cathode material for the electro-Fenton process: Comparison with carbon felt cathode and application to degradation of synthetic dye basic blue 3 in aqueous medium, $\mathrm{J}$. Electroanal. Chem. 616 (2008) 71-78. https://doi.org/10.1016/j.jelechem.2008.01.002.

[18] S. Chen, L. Tang, H. Feng, Y. Zhou, G. Zeng, Y. Lu, J. Yu, X. Ren, B. Peng, X. Liu, Carbon felt cathodes for electro-Fenton process to remove tetracycline via synergistic adsorption and degradation, Sci. Total Environ. 670 (2019) 921-931. https://doi.org/10.1016/j.scitotenv.2019.03.086.

[19] M.R. Haider, W.L. Jiang, J.L. Han, H.M.A. Sharif, Y.C. Ding, H.Y. Cheng, A.J. Wang, 
In-situ electrode fabrication from polyaniline derived N-doped carbon nanofibers for metal-free electro-Fenton degradation of organic contaminants, Appl. Catal. B Environ. 256 (2019). https://doi.org/10.1016/j.apcatb.2019.117774.

[20] T.X. Huong Le, M. Drobek, M. Bechelany, J. Motuzas, A. Julbe, M. Cretin, Application of Fe-MFI zeolite catalyst in heterogeneous electro-Fenton process for water pollutants abatement, Microporous Mesoporous Mater. 278 (2019) 64-69. https://doi.org/10.1016/j.micromeso.2018.11.021.

[21] S.O. Ganiyu, N. Oturan, S. Raffy, G. Esposito, E.D. van Hullebusch, M. Cretin, M.A. Oturan, Use of Sub-stoichiometric Titanium Oxide as a Ceramic Electrode in Anodic Oxidation and Electro-Fenton Degradation of the Beta-blocker Propranolol: Degradation Kinetics and Mineralization Pathway, Electrochim. Acta. 242 (2017) 344-354. https://doi.org/10.1016/j.electacta.2017.05.047.

[22] X. Xu, J. Cai, M. Zhou, X. Du, Y. Zhang, Photoelectrochemical degradation of 2,4dichlorophenoxyacetic acid using electrochemically self-doped $\mathrm{Blue} \mathrm{TiO} 2$ nanotube arrays with formic acid as electrolyte, J. Hazard. Mater. 382 (2020) 121096. https://doi.org/10.1016/j.jhazmat.2019.121096.

[23] A.U.R. Bacha, H. Cheng, J. Han, I. Nabi, K. Li, T. Wang, Y. Yang, S. Ajmal, Y. Liu, L. Zhang, Significantly accelerated PEC degradation of organic pollutant with addition of sulfite and mechanism study, Appl. Catal. B Environ. 248 (2019) 441-449. https://doi.org/10.1016/j.apcatb.2019.02.049.

[24] M.G. Peleyeju, E.H. Umukoro, L. Tshwenya, R. Moutloali, J.O. Babalola, O.A. Arotiba, Photoelectrocatalytic water treatment systems: Degradation, kinetics and intermediate products studies of sulfamethoxazole on a TiO2-exfoliated graphite electrode, RSC Adv. 7 (2017) 40571-40580. https://doi.org/10.1039/c7ra07399b.

[25] M.G. Peleyeju, O.A. Arotiba, Recent trend in visible-light photoelectrocatalytic systems for degradation of organic contaminants in water/wastewater, Environ. Sci. Water Res. Technol. 4 (2018) 1389-1411. https://doi.org/10.1039/c8ew00276b.

[26] G. Longobucco, L. Pasti, A. Molinari, N. Marchetti, S. Caramori, V. Cristino, R. Boaretto, 
C.A. Bignozzi, Photoelectrochemical mineralization of emerging contaminants at porous WO3 interfaces, Appl. Catal. B Environ. 204 (2017) 273-282.

https://doi.org/10.1016/j.apcatb.2016.11.007.

[27] S. Liu, M. Zhao, Z. He, Y. Zhong, H. Ding, D. Chen, Preparation of a p-n heterojunction 2D BiOI nanosheet/1DBiPO 4 nanorod composite electrode for enhanced visible light photoelectrocatalysis, Chinese J. Catal. 40 (2019) 446-457. https://doi.org/10.1016/S1872-2067(18)63186-9.

[28] M. Zhang, W. Pu, S. Pan, O.K. Okoth, C. Yang, J. Zhang, Photoelectrocatalytic activity of liquid phase deposited $\alpha$-Fe $<$ inf $>2</$ inf $>0<$ inf $>3</$ inf $>$ films under visible light illumination, J. Alloys Compd. 648 (2015) 719-725. https://doi.org/10.1016/j.jallcom.2015.07.026.

[29] L. Cheng, Y. Tian, J. Zhang, Construction of p-n heterojunction film of $\mathrm{Cu} 2 \mathrm{O} / \alpha-\mathrm{Fe} 2 \mathrm{O} 3$ for efficiently photoelectrocatalytic degradation of oxytetracycline, J. Colloid Interface Sci. 526 (2018) 470-479. https://doi.org/10.1016/j.jcis.2018.04.106.

[30] B.O. Orimolade, O.A. Arotiba, An Exfoliated Graphite-Bismuth Vanadate Composite Photoanode for the Photoelectrochemical Degradation of Acid Orange 7 Dye, Electrocatalysis. 10 (2019) 429-435. https://doi.org/10.1007/s12678-019-00534-5.

[31] E.H. Umukoro, N. Kumar, J.C. Ngila, O.A. Arotiba, Expanded graphite supported p-n MoS2-SnO2heterojunction nanocomposite electrode for enhanced photo-electrocatalytic degradation of a pharmaceutical pollutant, J. Electroanal. Chem. 827 (2018) 193-203. https://doi.org/10.1016/j.jelechem.2018.09.027.

[32] B.O. Orimolade, B.A. Koiki, G.M. Peleyeju, O.A. Arotiba, Visible light driven photoelectrocatalysis on a $\mathrm{FTO} / \mathrm{BiVO} 4$ /BiOI anode for water treatment involving emerging pharmaceutical pollutants, Electrochim. Acta. 307 (2019) 285-292. https://doi.org/10.1016/j.electacta.2019.03.217.

[33] H. Olvera-Vargas, J.C. Rouch, C. Coetsier, M. Cretin, C. Causserand, Dynamic cross-flow electro-Fenton process coupled to anodic oxidation for wastewater treatment: Application to the degradation of acetaminophen, Sep. Purif. Technol. 203 (2018) 143-151. 
https://doi.org/10.1016/j.seppur.2018.03.063.

[34] T.X.H. Le, C. Charmette, M. Bechelany, M. Cretin, Facile Preparation of Porous Carbon Cathode to Eliminate Paracetamol in Aqueous Medium Using Electro-Fenton System, Electrochim. Acta. 188 (2016) 378-384. https://doi.org/10.1016/j.electacta.2015.12.005.

[35] E.J. Ruiz, A. Hernández-Ramírez, J.M. Peralta-Hernández, C. Arias, E. Brillas, Application of solar photoelectro-Fenton technology to azo dyes mineralization: Effect of current density, Fe2+ and dye concentrations, Chem. Eng. J. 171 (2011) 385-392. https://doi.org/10.1016/j.cej.2011.03.004.

[36] T.X. Huong Le, L.F. Dumée, S. Lacour, M. Rivallin, Z. Yi, L. Kong, M. Bechelany, M. Cretin, Hybrid graphene-decorated metal hollow fibre membrane reactors for efficient electro-Fenton - Filtration co-processes, J. Memb. Sci. 587 (2019) 117182. https://doi.org/10.1016/j.memsci.2019.117182.

[37] E.H. Umukoro, M.G. Peleyeju, J.C. Ngila, O.A. Arotiba, Towards wastewater treatment: Photo-assisted electrochemical degradation of 2-nitrophenol and orange II dye at a tungsten trioxide-exfoliated graphite composite electrode, Chem. Eng. J. 317 (2017) 290301. https://doi.org/10.1016/j.cej.2017.02.084.

[38] K. Zhao, Q. Zeng, J. Bai, J. Li, L. Xia, S. Chen, B. Zhou, Enhanced organic pollutants degradation and electricity production simultaneously via strengthening the radicals reaction in a novel Fenton-photocatalytic fuel cell system, Water Res. 108 (2017) 293300. https://doi.org/10.1016/j.watres.2016.11.002.

[39] H. Liu, W. Yang, L. Wang, H. Hou, F. Gao, Electrospun BiVO 4 nanobelts with tailored structures and their enhanced photocatalytic/photoelectrocatalytic activities, CrystEngComm. 19 (2017) 6252-6258. https://doi.org/10.1039/c7ce01478c.

[40] C. Trellu, C. Coetsier, J.C. Rouch, R. Esmilaire, M. Rivallin, M. Cretin, C. Causserand, Mineralization of organic pollutants by anodic oxidation using reactive electrochemical membrane synthesized from carbothermal reduction of TiO 2, Water Res. 131 (2018) 310-319. https://doi.org/10.1016/j.watres.2017.12.070.

[41] R. Akbarzadeh, C.S.L. Fung, R.A. Rather, I.M.C. Lo, One-pot hydrothermal synthesis of 
g-C3N4/Ag/AgCl/BiVO4micro-flower composite for the visible light degradation of ibuprofen, Chem. Eng. J. 341 (2018) 248-261. https://doi.org/10.1016/j.cej.2018.02.042.

[42] C. Regmi, D. Dhakal, T.H. Kim, T. Yamaguchi, S.W. Lee, Fabrication of Ag-decorated BiOBr-mBiVO4 dual heterojunction composite with enhanced visible light photocatalytic performance for degradation of malachite green, Nanotechnology. 29 (2018) 154001. https://doi.org/10.1088/1361-6528/aaac60.

[43] T.X.H. Le, T. Van Nguyen, Z. Amadou Yacouba, L. Zoungrana, F. Avril, D.L. Nguyen, E. Petit, J. Mendret, V. Bonniol, M. Bechelany, S. Lacour, G. Lesage, M. Cretin, Correlation between degradation pathway and toxicity of acetaminophen and its byproducts by using the electro-Fenton process in aqueous media, Chemosphere. 172 (2017) 1-9. https://doi.org/10.1016/j.chemosphere.2016.12.060.

[44] S.O. Ganiyu, N. Oturan, S. Raffy, M. Cretin, C. Causserand, M.A. Oturan, Efficiency of plasma elaborated sub-stoichiometric titanium oxide ( $\mathrm{Ti} 4 \mathrm{O} 7$ ) ceramic electrode for advanced electrochemical degradation of paracetamol in different electrolyte media, Sep. Purif. Technol. 208 (2019) 142-152. https://doi.org/10.1016/j.seppur.2018.03.076.

[45] P.Y. Lee, C.Y. Chen, Toxicity and quantitative structure-activity relationships of benzoic acids to Pseudokirchneriella subcapitata, J. Hazard. Mater. 165 (2009) 156-161. https://doi.org/10.1016/j.jhazmat.2008.09.086. 